\title{
Using Behaviour Change as a Critical Frame of Reference to Understand the Adoption of Learning Design Methodologies in Higher Education
}

\author{
Maria Toro-Troconis ${ }^{1}$, Julie Voce ${ }^{2}$, Jesse Alexander ${ }^{3}$, Santanu Vasant ${ }^{4} \&$ Manuel Frutos-Perez ${ }^{5,}$ \\ ${ }^{1}$ Online Education Consultant, Cheshire, United Kingdom \\ ${ }^{2}$ Department of Learning Enhancement and Development, City, University of London, London, United Kingdom \\ ${ }^{3}$ Institute of Photography, Falmouth University, Falmouth, United Kingdom \\ ${ }^{4}$ Centre for Excellence in Learning and Teaching, University of East London, London, United Kingdom \\ ${ }^{5}$ Cambridge Education Group, Cambridge, United Kingdom \\ *Correspondence: Cambridge Education Group, Cambridge, United Kingdom. E-mail: \\ manuel.frutosperez@cambridgeonlinelearning.com
}

Received: February 22, $2021 \quad$ Accepted: April 2, $2021 \quad$ Online Published: April 12, 2021

doi:10.5430/wje.v11n2p1 URL: https://doi.org/10.5430/wje.v11n2p1

\begin{abstract}
This paper introduces the COM-B model (Capabilities-Opportunities-Motivation:Behaviour) and its use in combination with the Behaviour Change Wheel (BCW) in developing an intervention which aims to promote the adoption of learning design methodologies by academic staff working with learning technologists in Higher Education (HE). Qualitative structured interviews were conducted among members of staff from five UK universities based on the COM-B model to identify the main behavioural determinants for the use and implementation of learning design methodologies. The analysis suggests that the implementation of learning design methodologies/frameworks might be more likely to occur if academic staff and learning technologists' psychological capability, physical and social opportunities, and intrinsic and extrinsic motivations are addressed. The COM-B model and the BCW have been effective in the context of learning design to analyse the behaviour of academic staff and learning technologists when engaging in the design of online/blended learning programmes.
\end{abstract}

Keywords: learning design, online learning, blended learning, higher education, behaviour change

\section{Introduction}

The Behaviour Change Wheel (BCW) synthesises the common features of 19 frameworks of behaviour change identified in a systematic literature review (Michie et al, 2011). Some of the frameworks assumed that behaviour was primarily driven by beliefs and perceptions, unconscious biases and the social environment. The BCW synthesises the common features of those frameworks, creating a new model of behaviour broad enough that can be applied to any behaviour and setting. 


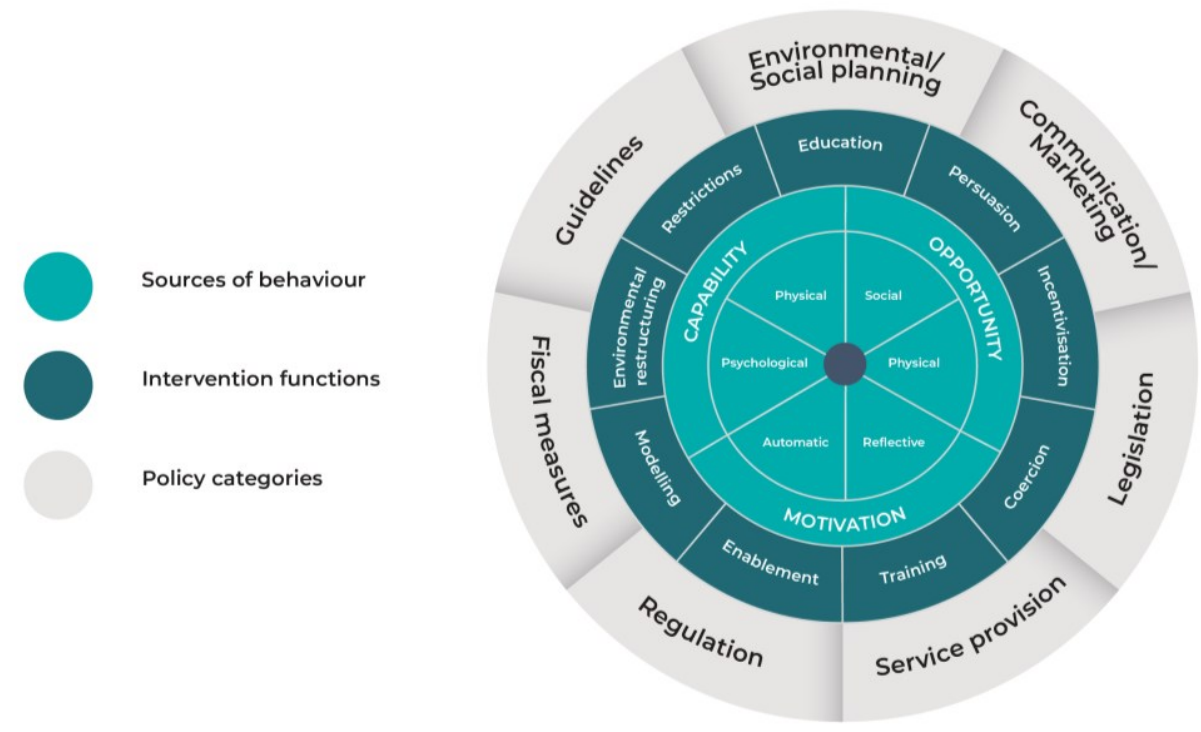

Figure 1. Adapted from 'The Behaviour Change Wheel' (BCW) - Michie et al. (2011)

The BCW allows the systematic identification of intervention functions and policy categories that could bring about change. Table 1 presents definitions of the nine intervention functions and seven policy categories.

Table 1. BCW - Intervention Function and Policy Category Definitions

\begin{tabular}{ll}
\hline & \\
\hline $\begin{array}{l}\text { Intervention function } \\
\text { Education }\end{array}$ & Increasing knowledge or understanding. \\
Persuasion & Using communication to induce positive or negative feelings or stimulate action. \\
Incentivisation & Creating an expectation of reward. \\
Coercion & Creating an expectation of punishment or cost. \\
Training & Imparting skills. \\
Restriction & Using rules to reduce the opportunity to engage in the target behaviour (or to increase \\
& the target behaviour by reducing the opportunity to engage in competing behaviours). \\
Environmental restructuring & Changing the physical or social context. \\
Modelling & Providing an example for people to aspire to or imitate. \\
Enablement & Increasing means/reducing barriers to increase capability (beyond education and \\
& training) or opportunity (beyond environmental restructuring). \\
Policy categories & Using print, electronic, telephonic or broadcast media. \\
Communication/marketing & Creating documents that recommend or mandate practice. This includes all changes to \\
Guidelines & service provision. \\
& Using the tax system to reduce or increase the financial cost. \\
Fiscal measures & Establishing rules or principles of behaviour or practice. \\
Regulation & Making or changing roles. \\
Legislation & Designing and/or controlling the physical or social environment. \\
Environmental/social planning & Delivering a service. \\
Service provision &
\end{tabular}

\section{The COM-B Model Proposes:}

'For someone to engage in a particular behaviour (B) at a given moment they must be physically and psychologically able $(\mathrm{C})$ and have the social and physical opportunity $(\mathrm{O})$ to do the behaviour and, in addition, want or need to do the behaviour more than any other competing behaviours at that moment.' (Baker et al., 2016, p.1). 
An analysis of the determinants of an identified behaviour (a desired behaviour not occurring or an undesired behaviour occurring) will help to identify what needs changing for the desired behaviour to occur or the undesired behaviour to cease. The $\mathrm{BCW}$ has been designed to support intervention designers in the process of behavioural analysis of a problem and subsequent intervention design supported by an evidence base. The BCW offers a systematic method of identifying intervention factors that may bring about change.

Considering its application to education, the COM-B model has been successfully applied in several medical education and clinical contexts (Ross et al., 2015; Barker et al., 2016; Beleigoli et al., 2018; Cornish et al., 2019; Courtenay et al., 2019; Ojo et al., 2019; Richardson et al., 2019; Keyworth et al., 2019; Maidment et al., 2020 and Reidy et al., 2020), but has not yet being applied in the area of learning design.

Learning design can be considered within a branch of educational sciences as a "design science" (Laurillard, 2012), aiming to guide academic staff when exploring educational problems and planning/implementing pedagogical practices (Conole, 2012).

The field of learning design has its roots in instructional design, sharing the common goal of assisting educators in the process of finding effective learning and teaching solutions: "learning designs" (Hernández-Leo et al. 2018). Learning design aims to support teaching and learning by providing a descriptive framework for teaching and learning activities using different types of delivery: online, face-to-face or blended.

'A learning design is a representation of what happens in a teaching and learning session to help learners achieve specific learning outcomes. It is often structured as a sequence of learning activities that can be shared with others. For online and blended learning, this approach is able to show, not only what is happening when the teacher is with the learners, but also what learners should be doing when the teacher is absent and they are being supported by technology.' (Laurillard et al., 2018, p.1046).

Several learning design frameworks and tools have evolved over the years with the common goal of supporting practitioners in making their learning designs explicit, shareable and reusable. Walker and Kerrigan (2016) explored how frameworks could support the development of teaching and learning within a digital context and encourage behavioural change in academic staff. Dalziel et al. (2016), represented core concepts of learning design using different levels of granularity (programme, module, session and learning activities). The research reported in this paper concentrates on the programme and module levels within a digital context.

This paper presents how the COM-B model and the BCW have been applied in the context of learning design to guide the development of an intervention to improve the use of learning design methodologies/frameworks when designing online/blended learning programmes/modules in Higher Education.

\section{Step 1: Define the Problem in Behavioural Terms}

The first step was to define the problem in behavioural terms (Michie et al., 2014), as presented in Table 2. The advantages of using pedagogically sound learning design frameworks/methodologies have been discussed extensively in the literature (Toro-Troconis et al., 2019; Rienties et al., 2017; Rienties and Toetenel, 2016; Toetenel \& Rienties, 2016; Laurillard, 2012; Conole et al., 2008; Masterman, 2009 and Sharpe et al., 2010).

However, the adoption of learning design approaches and tools is still very limited and challenging (Dagnino et al., 2018). Laurillard et al. (2018) conducted experimental research showing how digital technology is capable of fostering large-scale improvements in the professional development of teachers using technology enhanced learning. Hernández-Leo et al. (2018) discussed the potential reasons for these challenges, highlighting the need for learning design tools to be discipline specific and the lack of compatibility with institutional systems to support the conversion of learning designs into the institutional Virtual Learning Environments (VLEs).

\section{Step 2: Select the Target Behaviour}

The second step of the BCW is to identify a target behaviour that could address the behavioural problem. In this case, the intended behaviour is the systematic implementation and use of learning design methodologies/frameworks by learning technologists and academic staff in the design of online/blended learning programmes in Higher Education (HE). However, as explained in the literature (Blackmore and Blackwell, 2003), the intended behaviour may be dependent on other peoples' behaviours within HE institutions. 
Table 2. Defining the Problem in Behavioural Terms

\begin{tabular}{ll}
\hline Defining the Problem in Behavioural Terms \\
\hline What behaviour? & $\begin{array}{l}\text { Utilise pedagogically sound methodologies in the design of online/blended } \\
\text { learning modules/programmes. }\end{array}$ \\
& $\begin{array}{l}\text { Higher Education institutions. } \\
\text { Where does the behaviour occur? }\end{array}$ \\
Who is involved in performing the behaviour? & Academic staff and learning technologists. \\
\hline
\end{tabular}

A scoping exercise carried out by the authors focused on the low uptake in the use of learning design frameworks/methodologies, and resulted in a conceptual map of the system of behaviours that may be encouraged for long-term use and implementation of learning design frameworks/methodologies among academic staff and learning technologists in HE. Figure 2 describes the behaviours among key university stakeholders: senior/lead HE academic staff; validation/regulatory bodies/industry; ICT; library and student support; academic development teams and students.

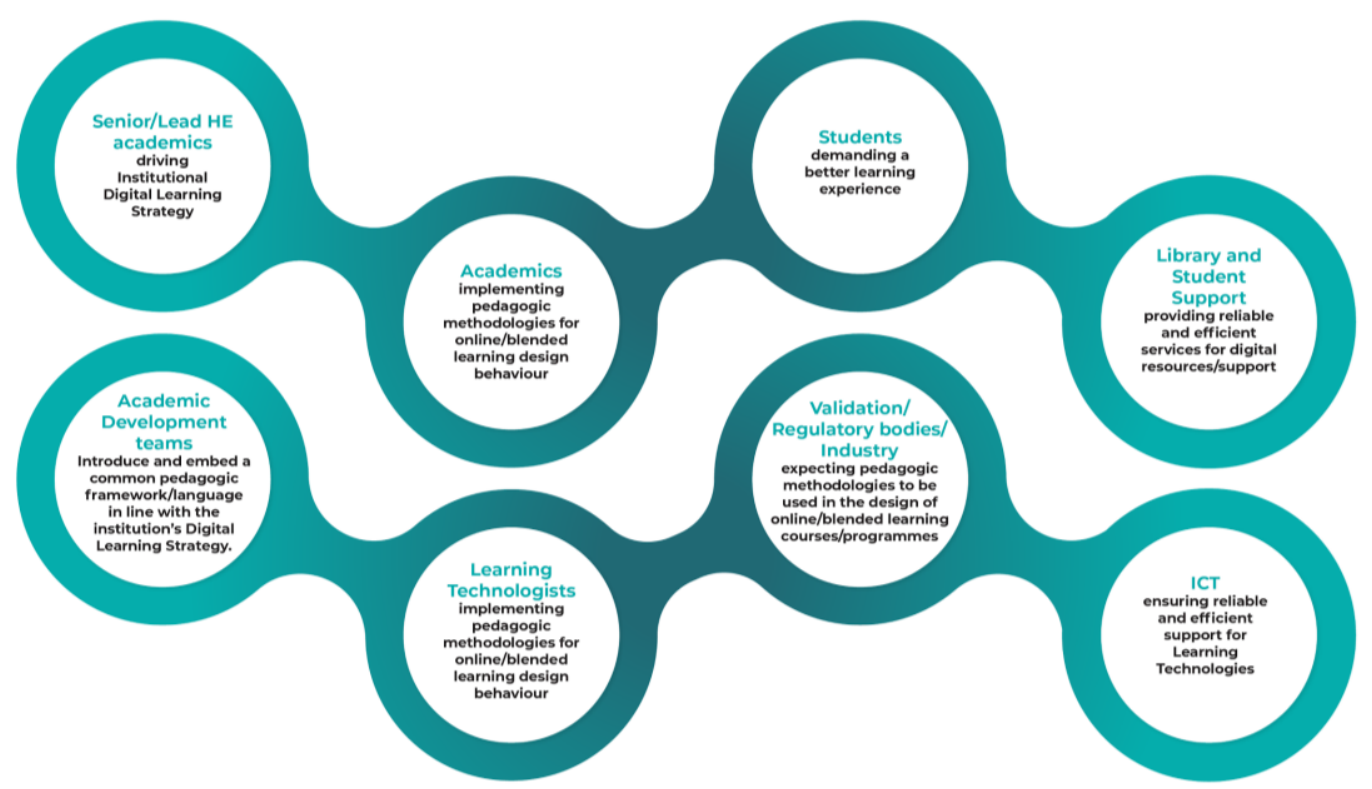

Figure 2. System of Behaviours Associated with the Implementation of Learning Design Frameworks/Methodologies

Table 3. Who Will Perform the Target Behaviours

\begin{tabular}{|c|c|c|c|c|}
\hline Who & What & Instruments & Where & When \\
\hline Academic staff & $\begin{array}{l}\text { Designing/re-designing } \\
\text { modules/programmes } \\
\text { using sound pedagogic } \\
\text { methodologies for } \\
\text { online/blended design. }\end{array}$ & $\begin{array}{l}\text { Learning design } \\
\text { frameworks/ } \\
\text { methodologies. }\end{array}$ & $\begin{array}{l}\text { Before } \\
\text { programme/course } \\
\text { validation; during } \\
\text { module/programme } \\
\text { design and } \\
\text { development. }\end{array}$ & $\begin{array}{l}\text { When designing/ } \\
\text { re-designing } \\
\text { online/blended } \\
\text { programmes. }\end{array}$ \\
\hline $\begin{array}{l}\text { Learning } \\
\text { technologists }\end{array}$ & $\begin{array}{l}\text { Support academic staff } \\
\text { when } \\
\text { designing/re-designing } \\
\text { modules/programmes } \\
\text { using a common } \\
\text { pedagogic framework. }\end{array}$ & $\begin{array}{l}\text { Learning design } \\
\text { frameworks/ } \\
\text { methodologies. } \\
\text { Examples of technical } \\
\text { interventions supported } \\
\text { by the university. }\end{array}$ & $\begin{array}{l}\text { Before } \\
\text { programme/course } \\
\text { validation; during } \\
\text { module/programme } \\
\text { design and } \\
\text { development. }\end{array}$ & $\begin{array}{l}\text { When supporting the } \\
\text { design/re-design of } \\
\text { online/blended } \\
\text { programmes. }\end{array}$ \\
\hline
\end{tabular}




\section{Step 3: Who Will Perform the Target Behaviours}

Table 3 presents the third step of the BCW which focuses on identifying who will perform the target behaviours, what they need to do to achieve change, and where and when they need to do it. This research focuses on the behaviours of academic staff and learning technologists, therefore only these roles have been presented in step 3 .

Step 4: Capability, Opportunity and Motivation

The fourth step is to apply the COM-B model to analyse whether the target users of the intervention (academic staff and learning technologists) have the capabilities, motivation and opportunities to develop the expected behaviour. This aspect was the focus of the research.

\section{Methods}

The Learning Design Bootcamp (LD Bootcamp, 2021) was used as the platform for this research. The Bootcamp provided an intensive three-month programme for academic staff and learning technologists engaging in the design and development of a 15 or 30-credit module of their choice (credit weighting according to the UK Higher Education Credit Framework). The university teams were supported with an initial face to face meeting, followed up by support from mentors during the design and development of their modules, and concluding with a final meeting to present their modules and experiences of the Bootcamp. At the final meeting, a panel of experts reviewed the presentations and chose a winner for the Bootcamp. All participants received a certificate to acknowledge their participation.

\subsection{Subjects}

A sample of five learning technologists and five academic staff involved in the Learning Design Bootcamp 2019 were invited to take part in the study. The academic staff included two senior lecturers, one lecturer, one course director and one academic developer. All the learning technologists involved in the study had more than 3-years of experience working in the area of learning technology in the UK.

Five HE institutions from the UK were selected to take part in the Learning Design Bootcamp 2019 and consented to take part in the research. The five HE institutions involved in the study were from different locations in the UK.

The universities selected were:

- The University of Warwick,

- Manchester Metropolitan University,

- Solent University,

- University of East London, and

- Stirling University.

The Course Design Sprint Framework (CoDesignS) was used as the learning design methodology during the study (Lewis, 2020; CoDesignS, 2019; Toro-Troconis et al., 2019; Toro-Troconis \& Aleksiev, 2018; Toro-Troconis et al., 2016). The CoDesignS framework derives from the Blended Learning Design Framework (BLEnDTC) developed at Imperial College London (Morton et al., 2016; Toro-Troconis, 2015).

Qualitative structured interviews using the $\mathrm{BCW}$ method were used to identify the determinants of behavioural planning. The questions for the structured interviews, developed following the $\mathrm{BCW}$ guidance, are available in Appendix A. Five researchers involved in the organising committee of the Learning Design Bootcamp conducted the interviews which took place over web-conferencing with either the academic member of staff or the learning technologist and the researcher present at the time of the interview. The interviews took place before the kick-off meeting for the Bootcamp.

The interviews were audio-recorded and transcribed to facilitate the coding of statements using the COM-B model. The transcription was carried out by an independent transcriber who received the recordings securely. The audio recordings were erased once the transcription was completed.

Anonymised transcripts of the structured interviews were analysed by two researchers using NVivo 10 software. The researchers met several times to discuss and compare their coding and resolve any discrepancies to analyse what would help identify the development of a behavioural plan in the use and implementation of learning design frameworks/methodologies.

The study was conducted according to a research protocol approved by the Research Integrity \& Ethics Committee at Falmouth University (Application reference RIEC/19/15). Data collection took place in March and April 2019. 


\section{Results}

This section outlines the results from the study by considering the findings from the learning technologists, followed by those from academic staff. In both cases the results are framed by the COM-B model by considering capabilities, motivation and opportunities.

\subsection{Learning Technologists}

\subsubsection{Capabilities}

Learning technologists reported a lack of physical capabilities in terms of space and tools when engaging in curriculum design.

"I mean, our physical spaces are limited. We have two main campuses. We've got one campus which contains older buildings and the rooms are very, very much based on a kind of, traditional behaviourist model of pedagogy."

Similarly, in relation to psychological capability, they reported a lack of skills and not enough training opportunities to know how to design online/blended learning modules.

"We're going to have to work in a certain way on this project because it is within a particular framework but I think that's really good actually. So, upskilling, certainly myself and the academics to work in a particular way will be really useful."

"Regarding sort of a learning design I'd say support is fairly limited to be honest. At my university I think we are a little bit behind on, sort of, online learning. We do have some offerings. But there is no, sort of, central setup"

"It would be nice to look at designing using a particular framework and theories of learning rather than maybe just using your own initiative and thinking."

Lack of resources associated with funding and not enough time to engage in the design of online and blended learning were highlighted several times.

"I think what jumps to mind is basically just time. I know it's not a physical barrier but it is a thing that would probably get in the way of most, sort of, that productive time. It's a time consuming process to design something from scratch"

"And academics are given quite...not very much time to redevelop or to develop new courses. So, that can be quite challenging."

"So, time is definitely...time and resources really I see as the biggest barriers to this."

The learning technologists also mentioned several times the lack of physical opportunities to engage with communities of practice in the area of learning design within the university and the lack of training and CPD opportunities available to them.

"I personally would find it very useful if there was some kind of...like a learning...digital learning or, you know, online learning sort of interest group within the university where practice got shared but it doesn't at the moment."

"I can't think of any social opportunities off the top of my head really. I suppose sharing if this project goes ahead, then we could share it with others across the university which would possibly benefit others and yes, sharing our practice and what we've done is certainly an option."

Several learning technologists mentioned the lack of leadership and digital strategy within their universities as the main problem when engaging with academic staff in the design of online/blended learning solutions.

"There's a challenge for us in how we make faculties aware of their need and of the support that we can provide for them in a way which doesn't appear like it is a threat or a comment on their own pedagogic skills and experiences."

"All undergraduate courses are undergoing a curricular review process at the moment. So, that involves getting all the course teams together. They're looking at redesigning their remits. So, it's...there's a big design focus there."

"The university is quite clearly expanding its online and digital provision but there doesn't necessarily feel there's a strategy for that." 


\subsubsection{Motivation}

Learning technologists mentioned they felt intrinsic and extrinsic motivations to learn and engage in learning design training and activities.

"We're interested in blended learning, in applying different principles...how that can be embedded into what we do."

"I'm interested to learn design principles. Something that you're very consciously doing."

"One of the key motivations is to do with the attainment gap that we have."

\subsubsection{Opportunities}

Physical and social opportunities were reported as important by the learning technologists. They were mostly concerned with the lack of physical opportunities in the form of frameworks, tools or guidelines to support the learning design dialogue with academic staff.

"I suppose it would improve my practice. And it would be nice to look at designing using a particular frameworks and theories of learning rather than maybe just using your own initiative and thinking."

"Most of the time, with no real design involved in the process. It's just a case of putting all kind of, your normal resources online and then calling it an online course."

"We're going to have to work in a certain way on this project because it is within a particular framework but I think that's really good actually. So, upskilling, certainly myself and the academics to work in a particular way will be really useful."

They also reported the lack of social opportunities to engage in communities of practice in the area of learning design.

"There's not really a network or an interest group established already, although it's something that I have considered doing because, for example, I'm not in a team so it makes it a little bit more challenging."

"I personally would find it very useful if there was some kind of...like a learning...digital learning or online learning sort of interest group within the university where practice got shared but it doesn't at the moment."

"We have an annual learning and teaching symposium which we run as a department and that gets a pretty fair proportion of all the academics from the university come along to that."

\subsection{Academic Staff}

\subsubsection{Capabilities}

Academic staff reported a key capability as having access to both learning technology support and training.

"[The learning technologist] does hold kind of open workshops for how we can develop different things, different quizzes, different kind of resources. And they are open, so he has drop-in sessions to do with that."

"Well, I know that we have a learning technologist who is [name]. But I think I'm probably the only person in our department that knows that we have this resource."

In terms of physical barriers, academic staff cited time and a lack of awareness of what is possible as the key capabilities.

\subsubsection{Motivation}

Academic staff cited an intrinsic motivation to improve the student experience, and in turn the students' feedback about the course, especially as some students are coming to university with an expectation of online delivery. They were keen to use technology and to explore a more blended approach for their teaching in order to enable a more flexible approach to learning for their students. There was an acknowledgement from several academic staff that their students are studying alongside other commitments, such as full-time jobs, or are studying from other locations around the world, so a more blended and online approach enables them to learn at their own pace.

"So, what we wanted to do on our course is to make it much more flexible and much more student led. So, we have to recognise that there are, sort of, face to face things that we need to do. But actually, students need to be able to learn at their own pace, when they have the time to learn. Not when we say they need to come to us to learn." 
"I'm quite keen to use as much technology as we can to improve the student experience."

"If they're coming from school, they've already done a bit of online learning from school. And I think we're missing a trick here. I think you could move to university where it could be done perhaps differently online, but certainly there's an expectation that a lot of teaching could be delivered online."

\subsubsection{Opportunities}

In terms of physical and social opportunities, academic staff mentioned that they would like to see more best practice advice and examples, either through events like a learning and teaching conference or as online case studies. They also talked about the value of workshops and events to provide peer support opportunities and the ability to hear what others are doing.

"We already have our CELT teaching and learning conference. And maybe some actual showcasing, or some actual kind of events within that conference where you could go and actually hear how somebody else set something up."

"I think if we had some best practice advice that would be very useful. Something that somebody else has tried and tested would always go down well, I think, with the staff."

"There's short courses that are run regularly and anybody can go along and get involved in them in small groups."

\section{Discussion}

This analysis forms the basis of an intervention design, using the BCW model (Michie et al, 2011), to encourage behavioural planning by learning technologists and subsequent use of learning design frameworks by academic staff in Higher Education. The BCW model can be applied in the context of learning design to analyse the behaviour of both academic staff designing online and blended solutions in HE and learning technologists working with them, providing support and guidance as part of the intervention design.

Dagnino et al. (2018) suggested that motivation, as a second-order barrier, was underexplored in the literature and it is clear from our findings that academic staff taking part in the Bootcamp were motivated by a desire to enhance the learning experience; however, the lack of digital learning strategies driving the systematic adoption of learning design methodologies, and the lack of time and space to encourage dialogue between learning technologists and academic staff in this area, seem to be the main barriers in the adoption of learning design methodologies.

Authors have highlighted similar issues in the literature:

'We see the need to devote time and resources to staff development in Higher Education on Design for Learning as an instrument to implement educational quality' (Ghislandi \& Raffaghelli, 2015, p. 281).

According to Masterman and Manton (2011), the key factors in the uptake of learning design practices are intrinsic motivation and sense of ownership, as well as institutional support. At the same time Bond et al. (2019) highlight in their review of five decades of educational technology research, how practitioners may benefit from further understanding of the instructional design process and closer relationships with design teams.

It is interesting to see how the recent findings from a Jisc survey (Langer-Crame et al., 2019) highlight that teaching staff in HE are mainly positive about the use of digital technologies in their work and many would like to use it more. However, as mentioned in the survey:

"Few teaching staff agree that they receive reward or recognition when they develop the digital aspects of their role. Levels of satisfaction in terms of continuous professional development and support for digital skills development are also low." (Langer-Crame et al., 2019, p.7).

“The main barrier to support my digital teaching practice is time." (Langer-Crame et al., 2019, p.49).

"Teaching online is currently a minority activity that requires time and consideration to develop and scale up. Many universities and colleges are not pursuing this agenda at the moment. However, if they want to move into providing more online courses, or offering live online options within blended courses, they will need to invest in building the relevant experience and expertise." (Langer-Crame et al., 2019, p.19).

Similarly, Bond et al. (2019) identified in their review the need of alternate models of professional development, such as large-scale professional development opportunities and enhanced/increased communities of practice as key implications for practice/policy. Hernández-Leo et al. (2018) also discussed how training in learning design has been 
identified as a priority and as an investment to support practitioners, improve teaching quality and innovation in their practice.

Interestingly, the Jisc results also show a correlation between teaching staff feeling well supported to develop the digital aspects of their roles and higher levels of student satisfaction with the quality of teaching and learning. This relates to the lack of training opportunities in learning design mentioned in this study, highlighting the value of investment in digital and learning design CPD.

" $57 \%$ of the teaching staff feel they do not have the time and support to innovate" (Langer-Crame et al., 2019, p.49).

The systematic method presented by the developers of the COM-B model and BCW has helped the researchers to use behavioural analysis to review the 2019 Learning Design Bootcamp. Feedback from the bootcamp mentors and the final review panel, who evaluated the presentations from the teams, identified that the teams had developed the behaviour to utilise pedagogically sound methodologies in the design of online/blended learning modules/programmes. However, in some cases the behaviour had only been developed in one of the roles, typically the learning technologist, and it was noticeable that team cohesion and buy-in from both roles was a key factor for the winning team.

The research and the review of the Bootcamp 2019 has enabled the identification of potential intervention functions which might bring about change within the HE institutions involved in the Learning Design Bootcamp 2020.

Table 4 below presents how more than one intervention function may influence several determinants identified in this study.

Table 4. Identification of Intervention Functions

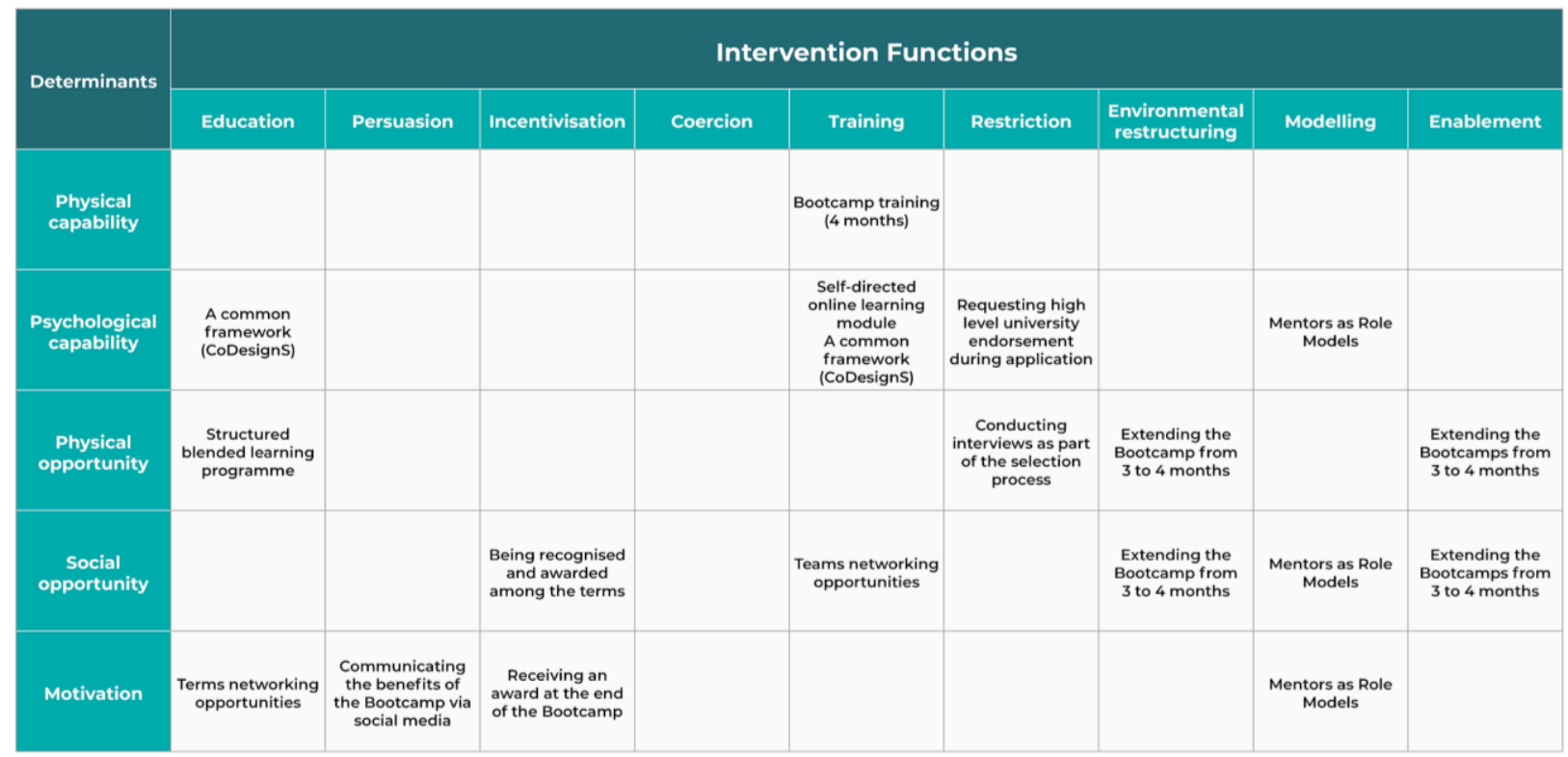

- Education will be used to address psychological capability by using a common design language or learning design framework (CoDesignS). It will also be used as a physical opportunity by offering a structured blended learning programme, and as motivation by offering the opportunity to create communities of practice in the area of Learning Design.

- Persuasion will be able to address motivation by communicating the benefits of the Bootcamp via social media and drawing on experiences from the 2019 participants.

- Incentivisation will be used to address social opportunity and motivation by providing opportunities to be rewarded for their work in the Bootcamp.

- Training will be used to address physical capability by extending the Bootcamp from three to four months. It will also be used to address psychological capability by offering a self-directed online learning module 
introducing the CoDesignS framework before the Bootcamp starts, and using a common learning design framework. Furthermore, it will also be used to create social opportunity by offering networking opportunities for the teams and creating communities of practice in the area of Learning Design.

- Restriction will be used to address psychological capability by requesting high level university endorsement at the application stage, addressing learning technologists' concerns about institutional buy-in both during and after the Bootcamp. It will also be used to address physical opportunity by conducting interviews as part of the selection process during the Bootcamp 2020.

- Environmental restructuring will be used to address physical and social opportunities by extending the Bootcamp 2020 from three to four months, and through the provision of a shared online course to introduce participants to each other and to the concept of Learning Design in advance of the first meeting.

- Modelling will be used to address psychological capability, social opportunity and motivation by offering mentors as role models during the Bootcamp. The mentors will guide and support the teams. Where possible, mentors will be former participants of the 2019 Bootcamp.

- Enablement will be addressed by providing physical and social opportunities by extending the Bootcamp from three to four months and increasing the number of sessions between the face to face meetings at the start and at the end of the Bootcamp.

All the criteria mentioned above and the behavioural analysis from the structured interviews are informing a complex intervention for the next Learning Design Bootcamp 2020 using the intervention functions: education, persuasion, incentivisation, training, restriction, environmental restructuring, modelling and enablement. This intervention aims to reduce barriers in the adoption of learning design methodologies by learning technologists and academic staff in HE institutions.

\section{Conclusions}

Using the COM-B model and the BCW (Michie et al., 2011) has helped us to better understand the capabilities, motivation and opportunities of academic staff and learning technologists taking part in the Learning Design Bootcamp, with a view to identifying interventions to improve the second iteration of the Bootcamp. The effectiveness of these interventions will be tested during the Bootcamp 2020 using a mixed-methods approach. It will assess what elements of the intervention are most effective in the adoption of learning design methodologies among learning technologists and academic staff from a global HE perspective. In response to the covid-19 pandemic, some of the interventions had to be modified, and in addition to reviewing the proposed interventions, it will be valuable to understand the role of the Bootcamp in supporting and preparing the participating institutions for a much wider move to online learning.

The adoption of collaborative behavioural planning among academic staff and learning technologists in the acquisition of learning design methodologies will require a complex intervention that addresses psychological capability, motivation, and physical and social opportunities. This will also need to take into account digital teaching practices in HE in order to support the design and delivery of robust, reliable and pedagogically-sound online and blended learning programmes.

In order to evaluate the elements of the intervention, further research will be needed to clarify the extent to which the intervention was effective. Further research is also encouraged from a community of practice point of view in order to assess the impact that the Learning Design Bootcamp has had in building learning design communities of practice.

\section{Availability of data and materials}

The datasets used and/or analysed during the current study are not publicly available due to privacy reasons but are available from the corresponding author on reasonable request.

\section{Funding}

This research was not funded.

\section{Acknowledgements}

The authors would like to thank Jannah Aljafri from Cambridge Education Group for her input and support as a Mentor; Mohamed Mahayni from Queen Mary University of London and Anita Holt from The University of 
Liverpool for their support as committee members; City, University of London for hosting the Learning Design Bootcamp 2019 and Cambridge Education Group for its support during the Bootcamp.

\section{References}

Barker, F., Atkins, L., \& de Lusignan, S. (2016). Applying the COM- B behaviour model and behaviour change wheel to develop an intervention to improve hearing-aid use in adult auditory rehabilitation. International Journal of Audiology, 55(3), 90-98. https://doi.org/10.3109/14992027.2015.1120894

Beleigoli, A., Andrade, A., Diniz, M., Alvares, R., Ferreira M., Silva, L., Rodrigues, M., Jacomassi, L., Cerqueira, A., \& Ribeiro, A. (2018). Using the Behaviour Change Wheel for Designing an Online Platform for Healthy Weight Loss - "POEmaS". Studies in Health Technology and Informatics, 254(1), 10. https://doi.org/10.2196/17494

Blackmore, P., \& Blackwell, R. (2003). Academic roles and relationships. In R. Blackwell \& P. Blackmore (Eds.), Towards Strategic Staff Development in Higher Education (pp. 16-28). Berkshire: Open University Press.

Bond, M., Zawacki-Richter, O., \& Nichols, M. (2019). Revisiting five decades of educational technology research: A content and authorship analysis of the British Journal of Educational Technology. British Journal of Educational Technology, 50(1), 12-63. https://doi.org/10.1111/bjet.12730

CoDesign, S. (2019). Course Design Sprint Framework. Retrieved 24 March, 2021 from https://codesignssite.wordpress.com/

Conole, G. (2012). Designing for Learning in an Open World. Milton Keynes, UK: Springer.

Conole, G., Brasher, A., Cross, S., Weller, M., Clark, P., \& Culver, J. (2008). Visualising learning design to foster and support good practice and creativity. Educational Media International, 45(3), 177-194. https://doi.org/10.1080/09523980802284168

Cornish, A., Jamieson, J., Raubenheimer, D., \& McGreevy, P. (2019). Applying the Behavioural Change Wheel to Encourage Higher Welfare Food Choices. Animals: An Open Access Journal from MDPI, 9(8), E524. https://doi.org/10.3390/ani9080524

Courtenay, M., Lim, R., Deslandes, R., Ferriday, R., Gillespie, D., Hodson, K., Reid, N., Thomas, N., \& Chater, A. (2019). Theory-based electronic learning intervention to support appropriate antibiotic prescribing by nurses and pharmacists: intervention development and feasibility study protocol. BMJ Open, 9(8), e028326. https://doi.org/10.1136/bmjopen-2018-028326

Dagnino, F., Dimitriadis, Y., Pozzi, F., Asensio-Pérez, J., \& Rubia-Avi, B. (2018). Exploring teachers' needs and the existing barriers to the adoption of Learning Design methods and tools: A literature survey. British Journal of Educational Technology, 49(6), 998-1013. https://doi.org/10.1111/bjet.12695

Dalziel, J., Conole, G., Wills, S., Walker, S., Bennett, S., Dobozy, E., Cameron, L., Badilescu-Buga, E., \& Bower, M. (2016). The Larnaca Declaration on Learning Design. Journal of Interactive Media in Education, 1(7), 1-24. http://dx.doi.org/10.5334/jime.407

Ghislandi, P., \& Raffaghelli, J. (2015). Forward-oriented designing for learning as a means to achieve educational quality. British Journal of Educational Technology, 46(2), 280-299. https://doi.org/10.1111/bjet.12257

Hernández-Leo, D., Asensio-Pérez, J. I., Derntl, M., Pozzi, F., Chacón, J., Prieto, L. P., \& Persico, D. (2018). An Integrated Environment for Learning Design Front. ICT, 5(9). https://doi.org/10.3389/fict.2018.00009

Keyworth, C., Epton, T., Goldthorpe, J., Calam, R., \& Armitage, C. (2019). 'It's difficult, I think it's complicated': Health care professionals' barriers and enablers to providing opportunistic behaviour change interventions during routine medical consultations. British Journal of Health Psychology, 24(3), 571-592. https://doi.org/10.1111/bjhp.12368

Langer-Crame, M., Killen, C., Francis, J., Beetham, H., Knight, S., \& Newman, T. (2019). Digital experience insights survey 2019: findings from teaching staff in UK further and higher education. JISC. Retrieved from digitalinsights.jisc.ac.uk/our-service/our-reports

Laurillard, D. (2012). Teaching as a design science: building pedagogical patterns for learning and technology. London: Routledge.

Laurillard, D., Kennedy, E., Charlton, P., Wild, J., \& Dimakopoulos, D. (2018). Using technology to develop 
teachers as designers of TEL: Evaluating the learning designer. British Journal of Educational Technology, 49(6), 1044-1058. https://doi.org/10.1111/bjet.12697

Learning Design (LD) Bootcamp (2021). Retrieved 24 March, 2021 from https://learningdesignbootcamp.com/

Lewis C. (2020). A Structured Approach to Online Learning Design in Dental Education. MedEdPublish, 9(1), 246. https://doi.org/10.15694/mep.2020.000246.1

Maidment, D., Coulson, N., Wharrad, H., Taylor, M., \& Ferguson, M. (2020). The development of an Health educational intervention for first-time hearing aid users: combining theoretical and ecologically valid approaches. International Journal of Audiology, 59(7), 1-9. https://doi.org/10.1080/14992027.2020.1755063

Masterman, E. (2009). Activity Theory \& the Design of Pedagogic Planning Tools. In L. Lockyer, S. Bennett, S. Agostinho, \& B. Harper (Eds.), Handbook of Research on Learning Design \& Learning Objects: Issues, Applications \& Technologies (pp. 209-227). Hershey, PA: IGI Global. https://doi.org/10.4018/978-1-59904-861-1.ch009

Masterman, E., \& Manton, M. (2011). Teachers' perspectives on digital tools for pedagogic planning and design. Technology, Pedagogy and Education, 20(2), 227-246. https://doi.org/10.1080/14759

Michie, S., Atkins, L., \& West, R. (2014). The Behaviour Change Wheel. A Guide to Designing Interventions. London: Silverpack Publishing.

Michie, S., van Stralen, M. M., \& West, R. (2011). The behaviour change wheel: A new method for characterising and designing behaviour change interventions. Implementation Sci., 6. https://doi.org/10.1186/1748-5908-6-42

Morton, C. E., Saleh, S. N., Smith, S. F., Hemani, A., Ameen, A., Bennie, T. D., \& Toro-Troconis, M. (2016). Blended learning: how can we optimise undergraduate student engagement? BMC Med Educ, 16. https://doi.org/10.1186/s12909-016-0716-Z

Ojo, S., Bailey, D., Brierley, M., Hewson, D., \& Chater, A. (2019). Breaking barriers: using the behavior change wheel to develop a tailored intervention to overcome workplace inhibitors to breaking up sitting time. $B M C$ Public Health, 19(1). https://doi.org/10.1186/s12889-019-7468-8

Reidy C., Foster, C., \& Rogers, A. (2020). A Facilitated Web-Based Self-Management Tool for People with Type 1 Diabetes Using an Insulin Pump: Intervention Development Using the Behavior Change Wheel and Theoretical Domains Framework. Journal of Medical Internet Research, 22(5), e13980. https://doi.org/10.2196/13980

Richardson, M., Khouja, C., Sutcliffe, K., \&Thomas, J. (2019). Using the theoretical domains framework and the behavioural change wheel in an overarching synthesis of systematic reviews. BMJ Open, 9(6), e024950. https://doi.org/10.1136/bmjopen-2018-024950

Rienties, B., \& Toetenel, L. (2016). The impact of learning design on student behaviour, satisfaction \& performance: a cross-institutional comparison across 151 modules. Computers in Human Behavior, 60, 333-341. https://doi.org/10.1016/j.chb.2016.02.074

Rienties, B., Nguyen, Q., Holmes, W., \& Reedy, K. (2017). A review of ten years of implementation and research in aligning learning design with learning analytics at the Open University, U. K. Interaction Design and Architecture(s), 33, 134-154.

Ross A., Reedy, G., Roots, A., Jaye, P., \& Birns, J. (2015). Evaluating multisite multiprofessional simulation training for a hyperacute stroke service using the Behaviour Change Wheel. BMC Medical Education, 15. https://doi.org/10.1186/s12909-015-0423-1

Sharpe, R., Beetham, H., \& De Freitas, S. (2010). Rethinking Learning for a Digital Age: How Learners are Shaping their Own Experiences, New York: Routledge.

Toetenel, L., \& Rienties, B. (2016). Analysing 157 learning designs using learning analytic approaches as a means to evaluate the impact of pedagogical decision making. British Journal of Educational Technology, 47(5), 981-992. https://doi.org/10.1111/bjet.12423

Toro-Troconis, M. (2015). Why we should pay more attention to E-learning? Journal of Health Specialities, 3(4), 191-197. https://doi.org/10.4103/1658-600X.166499

Toro-Troconis, M., \& Aleksiev, A. (2018). Does Learning Design have an effect on student performance? Aligning Learning Design with Learning Analytics. In Proceedings of the Association for Learning Technology Annual Conference 2018 (ALT-C 2018), University of Manchester, UK, 11-13 September. 
Toro-Troconis, M., Alexander, J., \& Frutos-Perez, M. (2019). Assessing Student Engagement in Online Programmes: Using Learning Design and Learning Analytics. International Journal of Higher Education, 8(6), 171-183. https://doi.org/10.5430/ijhe.v8n6p171

Toro-Troconis, M., Bridson, J-M., Halawa, H., Prescott, D., \& Edwards, S. (2016). Course Design Sprint Framework (CoDesignS). In Proceedings of the ALT Annual Conference 2016: Connect, Collaborate, Create. University of Warwick, UK, 6-8 September.

Walker, S., \& Kerrigan, M. J. P. (2016). Learning Design in the New Digital Age. In J. Dalziel (Ed.), Learning Design: Conceptualizing a Framework for Teaching and Learning Online (First, pp. 78-95). New York, New York, USA: Routledge Taylor and Francis Group.

\section{Appendix A}

Structured Interview Questions - Academic staff

1. Capabilities

- Please describe how your university supports you as an academic in the design of online/blended programmes/modules?

- How important is it for you and your School/Faculty to have learning design support in your area? How would that benefit your academic practice?

- Are there any physical barriers in the design of online/blended learning programmes/modules in your area? Please explain.

- $\quad$ Are there any physical capabilities needed to support you in the design of online/blended modules? i.e. space, physical skills, etc.

\section{Motivation}

- What would be the main motivation for you as an academic to be involved in the design of online/blended programmes/modules?

- Do you feel applying learning design principles in the design of online/blended programmes/modules should be implicit in your academic practice?

\section{Opportunities}

- Are there any social opportunities for you to engage in learning design practice within your university?

- What kind of social opportunities would benefit you in this context?

- Would any physical opportunities benefit you in this context? i.e. guidelines, frameworks, etc.

Structured Interview Questions - Learning technologists

\section{Capabilities}

- $\quad$ Please describe how your university supports you as a learning technologist in the design of online/blended programmes?

- How important is it for you and your School/Faculty to have learning design support in your area? How would that benefit your professional practice?

- Are there any physical barriers in the design of online/blended learning programmes/modules in your area? Please explain.

- $\quad$ Are there any physical capabilities needed to support you in the design of online/blended modules? i.e. space, physical skills, etc.

\section{Motivation}

- What would be the main motivation for you as a learning technologist to be involved in the design of online/blended programmes/modules?

- Do you feel applying learning design principles in the design of online/blended programmes/modules should be implicit in your professional practice?

\section{Opportunities}


- Are there any social opportunities for you to engage in learning design practice within your university?

- What kind of social opportunities would benefit you in this context?

- Would any physical opportunities benefit you in this context? i.e. guidelines, frameworks, etc.

\section{Copyrights}

Copyright for this article is retained by the author(s), with first publication rights granted to the journal.

This is an open-access article distributed under the terms and conditions of the Creative Commons Attribution license (http://creativecommons.org/licenses/by/4.0/). 